\title{
A generic approach to develop a trait-based indicator of trawling-induced disturbance
}

\author{
Olivier Beauchard ${ }^{1,2, *}$, Anik Brind'Amour ${ }^{3}$, Michaela Schratzberger ${ }^{4}$, \\ Pascal Laffargue ${ }^{3}$, Niels T. Hintzen ${ }^{5}$, Paul J. Somerfield ${ }^{6}$, Gerjan Piet ${ }^{5}$
}

\author{
${ }^{1}$ Netherlands Institute for Sea Research and Utrecht University, Department of Estuarine and Delta Systems, Korringaweg 7, \\ PO Box 140, Yerseke 4401 NT, the Netherlands \\ ${ }^{2}$ Ecosystem Management Research Group, University of Antwerp, Universiteitsplein 1, 2610 Wilrijk, Belgium \\ ${ }^{3}$ IFREMER, Unité Ecologie et Modèles pour l'Halieutique, rue de l'Ile d'Yeu, BP 21105, 44311 Nantes Cedex 3, France \\ ${ }^{4}$ Centre for Environment, Fisheries and Aquaculture Science, Lowestoft Laboratory, Pakefield Road, Lowestoft NR33 0HT, UK \\ ${ }^{5}$ Wageningen Marine Research, Wageningen UR, IJmuiden $1970 \mathrm{AB}$, the Netherlands \\ ${ }^{6}$ Plymouth Marine Laboratory, Prospect Place, Plymouth PL1 3DH, UK
}

\begin{abstract}
Biological trait analysis has become a popular tool to infer the vulnerability of benthic species to trawling-induced disturbance. Approaches using multiple traits are being developed, but their generic relevance across faunal components and geographic locations remains poorly tested, and the importance of confounding effects are poorly recognised. This study integrates biological traits of benthic species that are responsive to instantaneous effects of trawling (i.e. sensitivity) and traits expressing recoverability over the longer term (i.e. years). We highlight the functional independence between these 2 components in response to trawling, test the behaviours of single and combined traits and account for potential confounding effects of environment and trawling intensity on benthic communities through variation partitioning. Two case studies are considered: epibenthos from the Bay of Biscay and endobenthos of the Dutch sector of the North Sea. The response to trawling is most pronounced when multiple traits covering different aspects that determine population dynamics (i.e. sensitivity and recoverability) are combined, despite confounding effects between gradients of benthic production and trawling intensity, especially for endobenthos. The integration of traits reflecting both sensitivity and recoverability provides complementary information on the faunal response to trawling, bridging the gap between fishing impact assessments and benthic community status assessments.
\end{abstract}

KEY WORDS: Benthic macroinvertebrate $\cdot$ Bottom trawling $\cdot$ Natural history $\cdot$ Biological trait · Composite indicator $\cdot$ Time scale $\cdot$ Confounding effect

\section{INTRODUCTION}

The state of seabed habitats, and how benthic communities are affected by the physical disturbance caused by mobile bottom-fishing gears, can be assessed using well-established quantitative methods (Hiddink et al. 2017, Pitcher et al. 2017, Sciberras et al. 2018, Rijnsdorp et al. 2020). These are based on a simple equation for relative benthic status that includes parameters for the instantaneous effect caused by the passing of the gear, termed de-

*Corresponding author: olivier.beauchard@nioz.nl pletion, and recovery over the longer term. Ecosystem-based fisheries management now also requires an assessment of the state of seabed habitats in terms of their typical species composition, the abundance of particularly sensitive or fragile species or their functioning. At present, there is no consensus on how these different aspects of the benthic community are affected by fishing-induced physical disturbance in terms of both the depletion and the recovery processes, thereby hampering support to management decisions. 
Assessing the status of benthic communities does not generally take into account differences in life history characteristics that may affect organism responses to, and capacity of populations to recover from, changing environments (Tyler-Walters et al. 2009). Depletion and recovery rates following physical disturbance tend to be estimated for whole benthic communities in generic habitats (Kaiser et al. 2006, Sciberras et al. 2018) which may not be representative of specific aspects of the benthic community occurring in a local habitat. Consequently, the use of trait information to infer the vulnerability of species to disturbance by proxy is increasingly being explored as a complementary approach (Beauchard et al. 2017).

Tyler-Walters et al. (2009) introduced the concepts of species' 'intolerance' and 'recoverability' to trawling disturbance, subsequently developed further by Bolam et al. (2014) as 'instantaneous sensitivity' and 'long-term sensitivity'. Here, we expand such approaches, using the term 'sensitivity' to indicate the extent to which a species is likely to be affected by the passage of a trawl, and 'recoverability' to indicate the capacity of a population to recover from the disturbance and the timescale over which recovery will occur. Recent studies have considered the use of multiple traits for assessing the sensitivity of marine benthos to bottom trawling using composite indicators based on scored trait modalities (de Juan \& Demestre 2012, Bolam et al. 2014, Foveau et al. 2017, González-Irusta et al. 2018, Mérillet et al. 2018, Hinz et al. 2021). The general relevance of using functional traits in such a framework was confirmed in a study on the vulnerability of demersal fish assemblages to trawling, where the combination of catchability and resistance represented sensitivity while resilience represented recoverability (de Juan et al. 2020).

Scientific consensus exists on the mechanisms underlying the response of benthic communities to physical disturbance (hereafter 'trawling') on the sea floor (International Council for the Exploration of the Sea 2017a, Pitcher et al. 2017, Rijnsdorp et al. 2018). Organism densities can decline following the passage of a trawl, as a result of death or removal of the affected fauna (i.e. depletion). Recovery may take place after this initial effect, potentially until the community returns to its untrawled state. The latter depends on the intrinsic rate of natural increase of the species. Whether full recovery occurs or, if not, what alternative equilibrium the community may reach, depends on the magnitude and frequency of trawling, as well as the recovery potential of the com- munity. If trawling is sufficiently frequent, communities may not have time to recover entirely between trawling events, leading to longer-term shifts in community composition with increased dominance of less sensitive species and lower densities or extirpation of the more vulnerable species.

There is a simple trade-off between recoverability and vulnerability. Species with high intrinsic rate of natural increase are generally considered to have higher potential to recover to pre-disturbance densities, and consequently to be less vulnerable. The intrinsic rate of natural increase results from a combination of growth and reproductive traits that favour population expansion. However, other traits that are not directly related to population growth are also relevant to sensitivity and recovery. The importance of these traits may manifest at different spatio-temporal scales. For example, a trait related to sensitivity such as an armoured body may provide some defence from the immediate physical effects of a trawl, but only if the trawl makes contact with an individual directly. In addition to processes within the footprint of the trawl, such as growth of surviving fauna, recovery may also be influenced by traits reflecting larger-scale factors such as the ability of an organism to recruit and recolonise, or to actively migrate into the trawled area. These processes may be determined by the densities of adult organisms in adjacent (in case of mobility) or more distant (through larval transport) areas. It follows that species with low recovery potential may not be sensitive to disturbance, for example slow-growing species which are deep burrowers (Bergman \& van Santbrink 2000). Conversely, species with high recoverability may be sensitive if disturbance exceeds a frequency at which they are depleted, for example fragile epibenthic organisms such as Bryozoa including Flustra foliacea (Bitschofsky et al. 2011).

Usually, studies either focus on a single trait (i.e. longevity, Rijnsdorp et al. 2020) or combine several traits to explain the response of the benthic community to trawling. Such approaches, however, only cover part of the recovery aspect in case of a single trait and ignore entirely the depletion aspect in all cases. As part of a more comprehensive and generic approach, we used biological traits representing the instantaneous effect of the passage of a trawl, i.e. sensitivity, and traits representing the longer-term recoverability. We applied these to endobenthos from the Dutch sector of the North Sea and epibenthos from the Bay of Biscay. We hypothesized as follows: (1) traits reflecting the sensitivity and recovery of a benthic community to trawling are independent 
and provide complementary information on the community's vulnerability; (2) combined traits are more responsive to trawling than individual traits.

To test $H_{1}$, we defined a series of benthic community traits related to sensitivity and recoverability, and analysed the relationships between these traits to explore the degree of independence between the 2 components. Based on the 2 case studies, we tested $\mathrm{H}_{2}$ by analysing relationships between field organism density data weighted by those traits, and data on trawling intensity; these relationships were expected to be negative. Importantly, while doing this, we corrected for the potentially confounding effects of environmental variation on these relationships. Although this work is intended to provide information to support the development of a generic indicator accounting for the interdependence of sensitivity and recovery, we propose a specific version adapted to areas with long histories of fishing exploitation.

\section{MATERIALS AND METHODS}

\subsection{Biological traits}

Different biological traits from larval, juvenile and adult stages determine population vulnerability to trawling. Some traits are relevant to the instantaneous effect of the passage of a trawl ('sensitivity'), while entirely different traits may represent the capacity of organisms and their populations to recover from trawling ('recoverability').

\subsubsection{Sensitivity}

Some species are fragile and easily damaged, while others are more robust. A buried organism is less likely to be exposed to trawling than an epibenthic one, with a greater chance of survival as its burrowing depth increases. Direct exposure to trawling can be mitigated by body size. Smaller species are generally less sensitive than larger-bodied taxa, as the former can escape through a net more easily if captured (Bolam et al. 2014, González-Irusta et al. 2018). The sensitivity (SE) component of a benthic assemblage can therefore be expected to be a function of standardised body fragility, burrowing depth and body length. In previous and similar works, composite indicators were built by adding trait scores. In this context, multiplicative aggregation is preferable due to (possibly irrelevant) compensatory effects of additive aggregation (Gan et al. 2017). For instance, a small body length (low sensitivity) buffers the high sensitivity of epibenthic living mode: the low sensitivity score of the former penalizes the high sensitivity score of the latter, more by multiplication than addition (e.g. $1 \times 3<1+3$ ); such scores are presented in more detail in Section 2.2 (see also Table 1). With this in mind, SE is defined here as:

$$
\mathrm{SE}=\mathrm{FR} \times \mathrm{BD} \times \mathrm{BL}
$$

where FR is fragility, BD is burrowing depth, and BL is body length.

\subsubsection{Recoverability}

Mobile species are likely to recolonise a trawled area by migrating more quickly than less mobile species, so recoverability is likely to be a function of motility (MO). Recoverability also depends on recruitment from larval settlement and subsequent growth to the adult stage. Late-maturing, slow-growing or poorly-recruiting species will all have low recoverability (MacDonald et al. 1996). Life span (LS), as used in the 'longevity approach' of Rijnsdorp et al. (2018), and age at maturity (AM) are traits of critical importance. Some species require a long time to achieve minimal reproductive success, including those with the naturally high juvenile mortality that is often driven by stochastic environmental conditions (Kindsvater et al. 2016).

LS is expected to respond negatively to trawling intensity in habitats dominated by species that live for years or even decades (Rijnsdorp et al. 2020), as are often encountered in rarely disturbed benthic habitats (e.g. coral reefs). However, in areas where the seafloor has been intensively trawled for more than a century, such as the European continental shelves, the individual and biomass densities of long-lived organisms may be too low to detect significant trawling effects. In such areas, and especially under high trawling frequencies, AM expresses a more relevant critical aspect of the life cycle, namely the chance of achieving at least one reproduction before being killed by a trawl, especially if reproductive life span $(R L S=L S-A M)$, for the same AM, is reduced compared to truly long-lived species. In general, AM is correlated with LS (Charnov 1993), and AM may account for a potential LS-effect. However, this relationship is not perfect when considering several phyla or limited spatial biogeographic extent. The AM/RLS ratio emphasises the critical time necessary to reach maturity and achieve reproductive success over a shorter RLS. For the same AM, very long-lived species, as- 
sumed to be largely depleted in intensively trawled areas, perform less successfully. However, the simple AM/RLS ratio can take the same value for species with different AM and RLS, so a species maturing at $1 \mathrm{yr}$ of age and dying after $2 \mathrm{yr}$ is assigned the same value as another species maturing at $2 \mathrm{yr}$ and dying after 4 yr. To counteract this, the ratio can be multiplied by AM to introduce an appropriate penalty for RLS in long-lived species with late AM. We call the resultant term relative maturity (RM), with 1 added to RLS to deal with cases where LS = AM (semelparity, in which case RLS $=0$ ), both measured in years:

$$
\mathrm{RM}=\frac{\mathrm{AM}}{\mathrm{RLS}+1} \times \mathrm{AM}
$$

These age-related aspects are of paramount importance in life history strategies of organisms (Charnov 1993), but some independent traits relevant to reproduction and offspring may be complementary. In the marine benthos, offspring can be released by parents at different developmental stages, depending on the species, with different chances of survival before settling as juveniles. Broadcasted eggs in the water column are more vulnerable to planktotrophy than brooded larvae, and both are more vulnerable than juveniles released as 'miniature adults' after internal incubation (Giangrande et al. 1994, Pechenik 1999). Large eggs have a shorter critical pelagic phase, because of faster development, than smaller ones (Giangrande et al. 1994, Giangrande 1997). The potential for recovery (RE) of the benthic community will therefore be a function of motility (MO), offspring type (OT) and offspring size (OS) as well as RM. Generally, OS is negatively correlated with fecundity due to the constraints of energetic allocation (Kindsvater et al. 2016), whereas OT can be independent of fecundity (e.g. many bivalves broadcast millions of eggs, and some crabs brood millions of larvae). Hence, RE includes many relevant aspects of species' life histories, and is defined here as:

$$
\mathrm{RE}=\mathrm{RM} \times \mathrm{MO} \times \mathrm{OT} \times \mathrm{OS}
$$

\subsubsection{Vulnerability}

Finally, we defined vulnerability by combining SE and RE by addition and multiplication ( $\mathrm{SE}+\mathrm{RE}$ and $\mathrm{SE} \times \mathrm{RE}$, respectively). Although we preferred multiplicative aggregation within the SE and RE components, we expected some independence between $\mathrm{SE}$ and RE, so that the 2 components could addi- tively compensate each other without synergy (Gan et al. 2017). Hence, both additive and multiplicative variants of the combined components were calculated to compare their distributions and associated variations.

We tested $H_{1}$ on the fauna from 2 case studies for which we compiled the described traits from the literature (Section 2.2). Then, prior to testing $\mathrm{H}_{2}$, we compared SE and RE distributions to assess their degree of variation, especially between the additive and multiplicative variants of vulnerability. As part of testing $\mathrm{H}_{2}$, for each case study, the taxa $\times$ traits matrix (including individual traits, trait combinations, SE, RE and vulnerability) was combined with survey data to examine relationships between trait-weighted organism densities and trawling intensity.

\subsection{Trait data}

Trait data were sought for all taxa found in the 2 case studies (see Table S1.1 in Supplement 1 at www.int-res.com/articles/suppl/m675p035_supp. pdf, mostly at the species and genus level. Trait information was obtained from peer-reviewed articles ( $\mathrm{n}=466)$, with additional books and book chapters (27), academic theses (25) and documents from the grey literature (14). Online data bases (7) were used when source information was not accessible. Trait information for the Bay of Biscay was complemented using the MERP Trait Explorer (Marine Ecosystem Research Programme 2021). In some cases, in absence of information at the species level, information of species from the same genus was used. For the Dutch exclusive economic zone (EEZ), we were able to obtain functional trait information for species that accounted for 94 and $85 \%$ of individual and biomass densities, respectively. For the Bay of Biscay, these percentages reached 87 and $95 \%$ respectively, after removing highly mobile species (fish and large cephalopods). Traits of 330 taxa in total were documented, 195 from the Dutch EEZ and 148 from the Bay of Biscay. Only 13 taxa were common to both case studies. Functionally, there were 217 unique trait combinations, 146 for the Dutch EEZ and 92 for the Bay of Biscay, with 21 trait combinations in common.

Most traits had ordinal modalities. These were ranked according to their responsiveness to trawling in such a way that all responses to trawling were expected to be negative. No a priori weights could be attributed to the traits, so they were considered to be 
Table 1. Traits and their modalities. Scores express the relative degree of responsiveness of each trait to physical disturbance

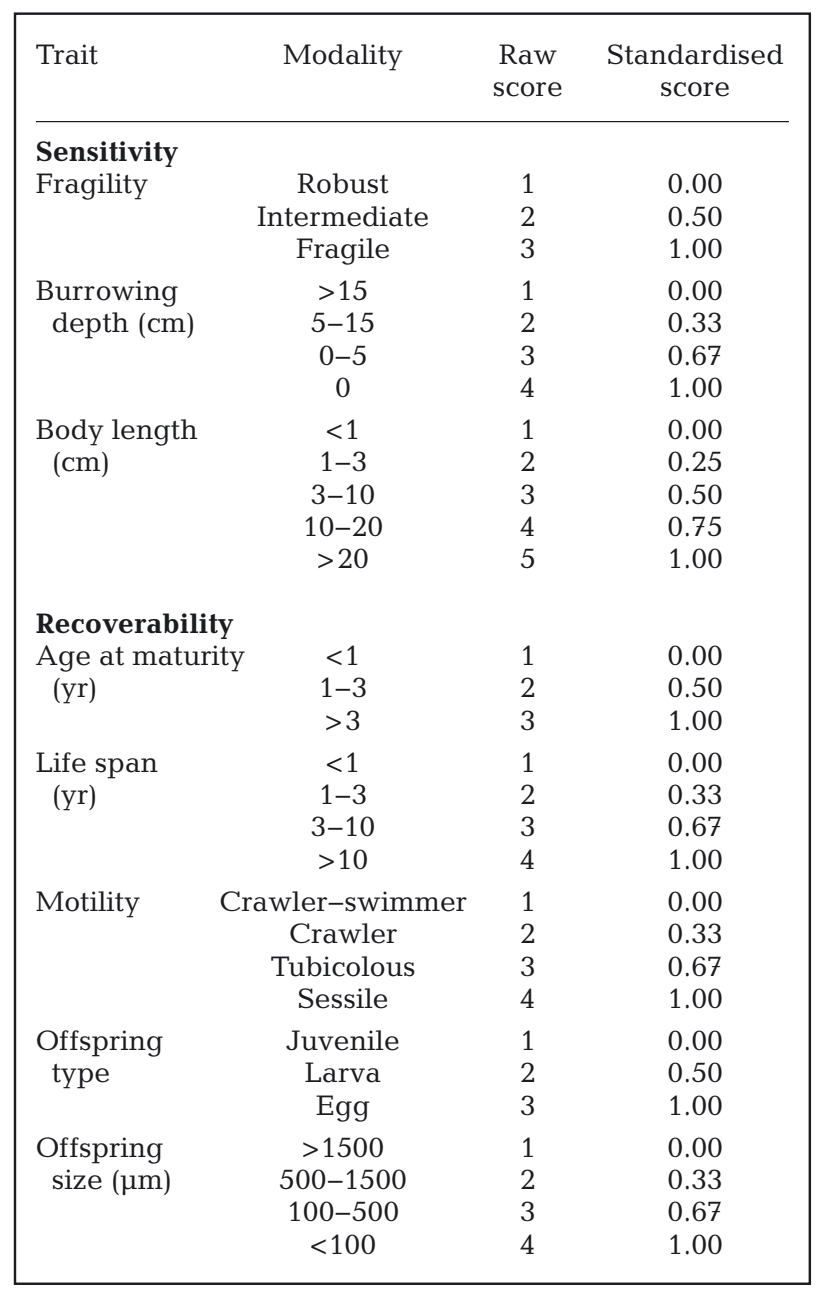

of equal importance and simply standardised to range between 0 and 1 . Traits, their modalities and scores are shown in Table 1.

\subsection{Benthic survey data}

The responsiveness to trawling intensity of individual traits, and SE and RE components separately and in different (additive and multiplicative) combinations, were tested using benthic data from 2 case studies: endobenthos from the Dutch EEZ and megaepibenthos from the Bay of Biscay, sampled using box corer and trawl, respectively (Fig. 1). The trawl proportionally samples larger organisms and more efficiently epibenthic and dispersed species. Hence, differences in functional attributes of the 2 faunas were expected given the contrasting sampling techniques.

\subsubsection{Dutch EEZ}

The study area spreads from $2.68^{\circ}$ and $6.60^{\circ} \mathrm{E}$ in longitude and from $51.30^{\circ}$ and $55.50^{\circ} \mathrm{N}$ in latitude. Its bottom, from shallow to deeper areas $(50 \mathrm{~m})$, is mostly sandy with local mud patches, especially in the deep northern part (Oyster Ground), characterised by much lower tidal velocities than in the south. Stations $(\mathrm{n}=79)$ (Fig. 1a), excluding coastal stations heavily impacted by shrimp trawling, were sampled annually from 1995 to 2010, and then in 2012 and 2015. Sediment was sampled with a box corer (1 core per station, $0.08 \mathrm{~m}^{2}, 15 \mathrm{~cm}$ deep), and macrozoobenthos was separated using a $1 \mathrm{~mm}$ mesh. Detailed information on the sampling procedure was provided by Daan \& Mulder (2009). The resultant dataset consists of biomass (ash-free dry weight) and number of individual organisms. Associated abiotic variables were particulate organic matter and carbon (measured from field samples), means of monthly median bottom current speed $\left(\mathrm{m} \mathrm{s}^{-1}\right)$ and bottom wave energy $(\mathrm{Pa})$ (modelled from Deltares Institute, Delft, The Netherlands), depth (European Monitoring Observatory and Data Network; EMODnet Bathymetry Consortium 2018) and primary productivity (mg C m $\mathrm{d}^{-1}$, modelled from Baretta et al. 1995).

\subsubsection{Bay of Biscay}

The study area ranges between the edge of the shelf in the west $\left(8^{\circ} \mathrm{W}\right)$ and the coast in the east $\left(1.5^{\circ} \mathrm{W}\right)$, and between $43.7^{\circ} \mathrm{N}$ at the northern margin of Gulf of Cap Breton in the south and $48.8^{\circ} \mathrm{N}$ in the north (Fig. 1b). The slope of the shelf is generally gentle (around $0.5 \%$ ), and the bottom is dominated by unconsolidated sediments composed mainly of sand and muddy sand, except in a large area in the north and on the continental slope where mud dominates. A total of 523 stations were considered (65 stations on average each year), covering mainly the soft-bottom habitats of the continental shelf (50-200 $\mathrm{m})$, including some stations on the upper slope (200-735 m). In the ongoing French Groundfish Survey in the Celtic Sea and Bay of Biscay (Mahe \& Laffargue 1987), a 36/47 Grande Ouverture Verticale trawl is used, with a $20 \mathrm{~mm}$ mesh cod-end liner, to sample benthic assemblages. Each haul lasts for approximately $30 \mathrm{~min}$ (sampled surface area of about $70000 \mathrm{~m}^{2}$ ). To be consistent with available fishing pressure data, we used epibenthic macroinvertebrate data (wet biomass and number of individuals) covering the period from 2009 to 2016. We also 

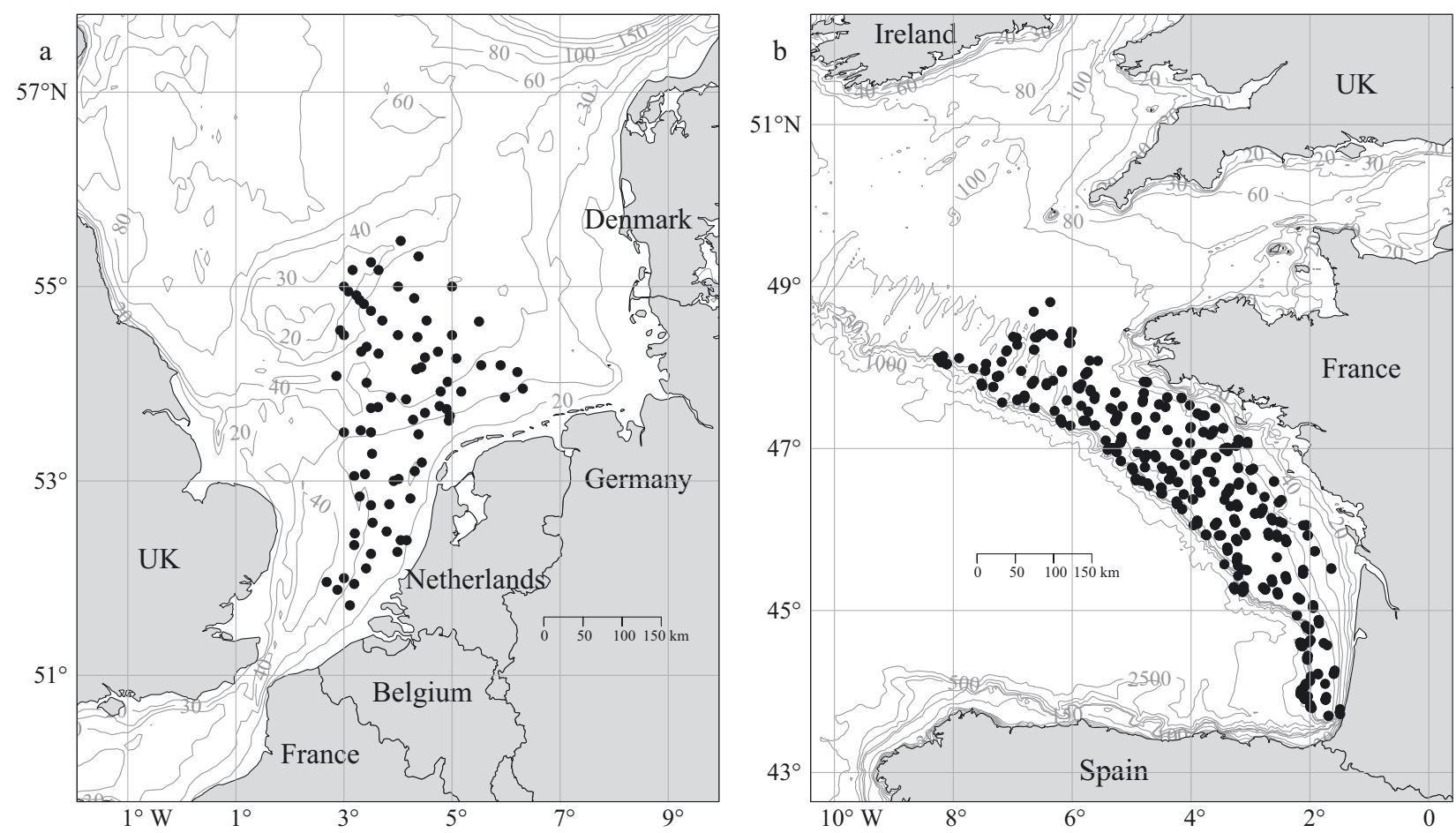

Fig. 1. Case studies. (a) Dutch exclusive economic zone (EEZ), (b) Bay of Biscay. Black dots show sampling stations; grey contours are isobaths displaying depth $(\mathrm{m})$

selected data deeper than $50 \mathrm{~m}$ to reduce the bias due to incomplete effort data for fishing vessels smaller than $12 \mathrm{~m}$ long that mainly operate in the shallower areas. Associated abiotic variables include mean annual bottom temperature, mean bottom salinity and the bottom current speed, obtained from the outputs of the MARS 3D model (Lazure \& Dumas 2008), sediment characteristics derived from discrete sediment categories (Bouysse et al. 1986, SHOM 2014) and depth recorded during the surveys (Mahe \& Laffargue 1987).

\subsection{Trawling intensity}

In the Dutch EEZ, a large part of the fishery that geographically takes place in the southern North Sea are beam trawls with gear width of $24 \mathrm{~m}$ and penetration depths $>2 \mathrm{~cm}$ for a large part of the gear (see Rijnsdorp et al. 2020 and Hintzen et al. 2021 for more details). Shrimp trawls are common all along the Dutch, German and Danish coastlines with a gear of $9 \mathrm{~m}$ on either side. Penetration depth in the sediment is generally shallow due to the light gear used. Commercial fisheries in the Bay of Biscay target various stocks in different ways. Bottom trawlers account for nearly $29 \%$ of the fleet (slightly more than 400 vessels). These vessels have an average size of about $15 \mathrm{~m}$ and target demersal and benthic species, using mainly bottom otter trawls with a width of about 50 to $100 \mathrm{~m}$ between the trawl doors, depending on the size or power of the vessels. A proportion of vessels also use twin trawls for Nephrops norvegicus, especially in the northern part. Gear penetration depth is difficult to evaluate due to their disparity.

This study covers the period 2010-2015 for the Dutch EEZ, and the period 2009-2016 for the Bay of Biscay. To estimate fishing pressure, vessel monitoring system (VMS) data in combination with logbook data were used to estimate the surface area fished between consecutive to relate VMS pings to a specific fishing gear and specific fishing practice (speedbased rule, Eigaard et al. 2016). The logbooks furthermore provide information on gear width or vessel power that were used to estimate gear width for otter trawls and flyshoot. Fishing effort was quantified as the sum of the area covered by a fishing gear over $1 \mathrm{yr}$ divided by a $0.05^{\circ} \times 0.05^{\circ}$ grid cell. This swept area ratio (SAR) was calculated for the year preceding the sampling date in both case studies. In the North Sea study area, trawling intensity was computed according to van Denderen et al. (2015). For the Bay of Biscay, we utilized the surface abrasion dataset computed from the International Council for 
the Exploration of the Sea (2017b) and the publicly available OSPAR database (Convention for the Protection of the Marine Environment of the North-East Atlantic 2017).

\subsection{Data analyses}

To test $H_{1}$, we investigated the relationships between traits and SE and RE components across taxa, using centred principal component analysis (PCA) of the species $\times$ standardised traits matrices from the 2 case studies. The use of traits independently of field data ensured equal weights for vulnerable and resilient or resistant taxa to reflect an ideal non-disturbed pattern. Complementarily, we analysed the distributions of the synthetic SE, RE and vulnerability $(\mathrm{SE}+\mathrm{RE}$ and $\mathrm{SE} \times \mathrm{RE})$ traits that could account for specific benthic signatures such as skewness or multimodality.

To test $H_{2}$, for each case study, traits were combined with survey data by aggregating organism densities per station and per trait to generate sampling-stations $\times$ response variables matrices (community weighted mean, CWM; for a community, sum of products between taxon densities and taxon trait scores; Kleyer et al. 2012). Prior to calculating CWM, all individual and combined traits within SE and RE were computed in each taxa $\times$ standardised traits matrix, generating 26 response variables, as well as the $\mathrm{SE}+\mathrm{RE}$ and $\mathrm{SE} \times \mathrm{RE}$ variables.

Six different types of organism densities were incorporated into stations $\times$ taxa matrices: biomass $\mathrm{m}^{-2}$, number of individuals $\mathrm{m}^{-2}$ and number of taxa $\mathrm{m}^{-2}$ as absolute values and also as relative values calculated by dividing absolute values by sample totals. The testing of several types of faunal data in the community matrices accounts for the fact that different types of data may be more relevant in different components of the benthos (macrobenthos or megabenthos) sampled using different gears and protocols. Analyses based on different types of data may also inform on different processes within the community. For instance, species biomass provides a more direct measure of resource use than abundance, as energy flow is known to vary with biomass (Valiela 2015). However, absolute densities generally reflect faunal responses along gradients of production, and not necessarily specific functional aspects independent of production. For instance, the use of relative densities is relevant to conservation purposes when functional aspects are given priority over total abundance. Thus, a habitat may be considered vulnerable if it is dominated by vulnerable taxa regardless of their total abundance.

Then, in order to compare the relative effects of abiotic variables and trawling intensity on the CWM traits, we decomposed the variance of each response variable, accounting for the effects of environmental variables and trawling intensity using variation partitioning (Legendre \& Legendre 2012). In general, benthic communities are not randomly distributed, and environmental conditions that may benefit or exclude some species may also benefit fishing (e.g. benthic primary productivity; Hintzen et al. 2021). As a consequence, a significant indicator response to trawling can be a spurious effect if an environmental variable is also correlated with the response and is the true explanation of the variation (i.e. a confounding effect). Therefore, to capture the pure trawling effect, response variation to trawling intensity was analysed by partial correlation, after removing the variance of environmental variables common to response and trawling intensity variables. Variation partitioning proceeds linearly and variables were therefore ln-transformed prior to analysis. For a detailed explanation of the procedure, see an example from the analyses in Supplement 2. Fig. 2 summarises our analytical approach.

Analyses were done with R 4.0.3 (R Core Team 2020); PCA with the package 'ade4' (Chessel et al. 2004), and variation partitioning with the package 'vegan' (Oksanen et al. 2010).

\section{RESULTS}

\subsection{Functional aspects of the studied faunas}

Despite differences in geography and sampling methods, the distributions of trait modalities were broadly similar between the 2 faunas (Fig. S3.1 in Supplement 3). As expected, higher proportions of taxa $>3 \mathrm{~cm}$ body length with shallower burrowing ability were found in the trawls from the Bay of Biscay. To a lesser extent, higher proportions of robust taxa and taxa with larvae of large size were also more characteristic of the Bay of Biscay. Species with short life spans $(<1 \mathrm{yr})$ and dispersing as juveniles were more prevalent in the Dutch EEZ endobenthos.

\subsection{Trait relationships}

PCA ordinations (Fig. 3) display the relationships between traits for each of the 2 faunas. In both case 

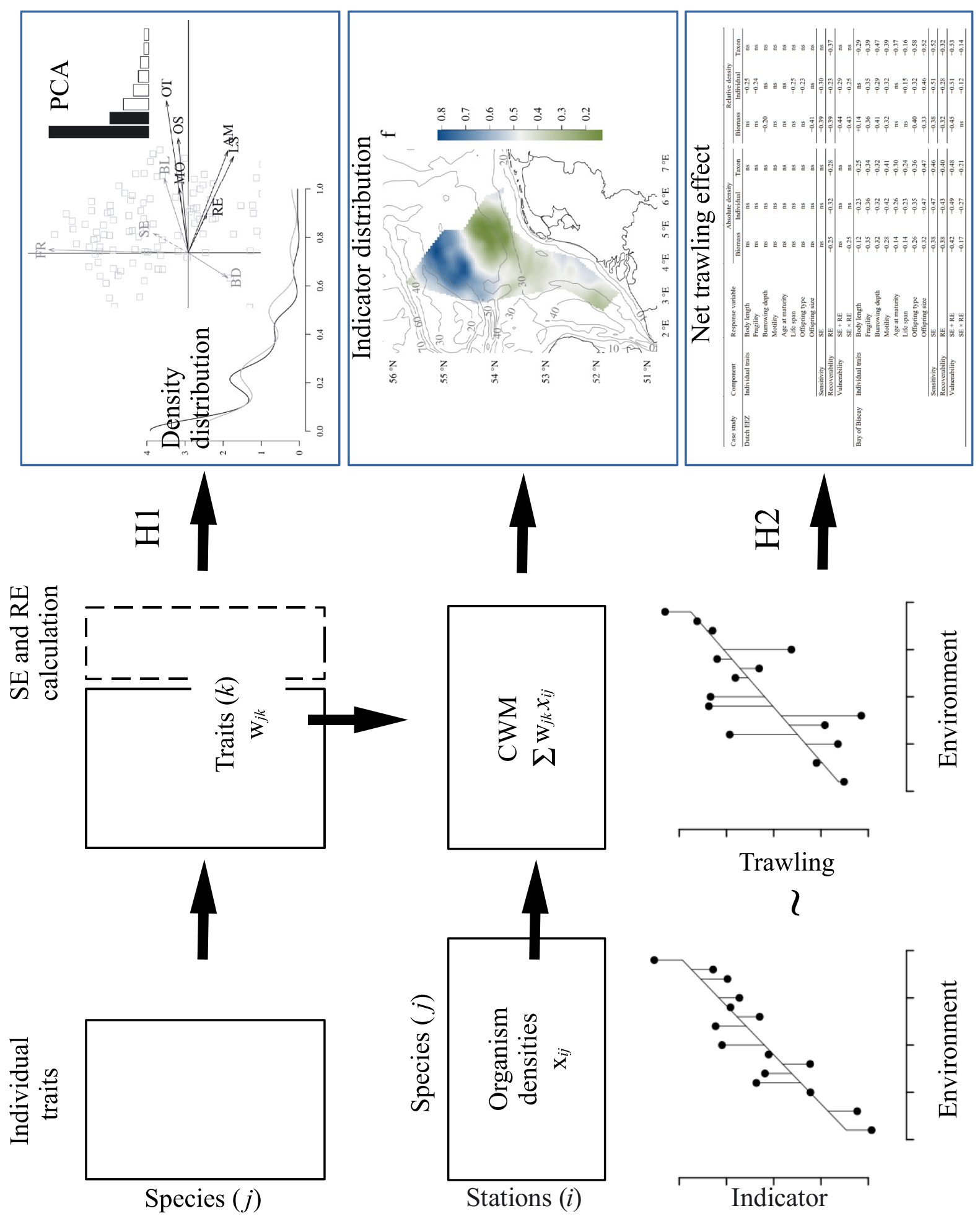

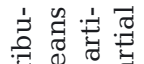

业

$\tau$ to 0

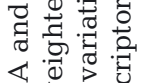

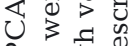

궁

블

द्व

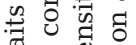

호ㅇㅝㅖ 웜

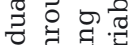

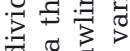

寻䒕要

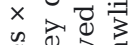

0

क ज

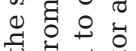

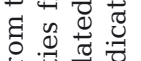

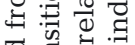

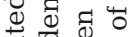

굴 छ

गु है है

80

융

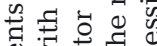

उ 0

용

o

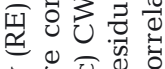

可矛

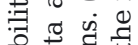

웡 웅

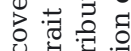

计

可

व

留志总

त 떤

5 च

政

둥메

ส

نे

일월

ฮี ซ 륨

중

중

구ㅇㅝㅠ

घี क्षे

ज त्व

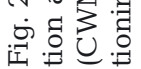




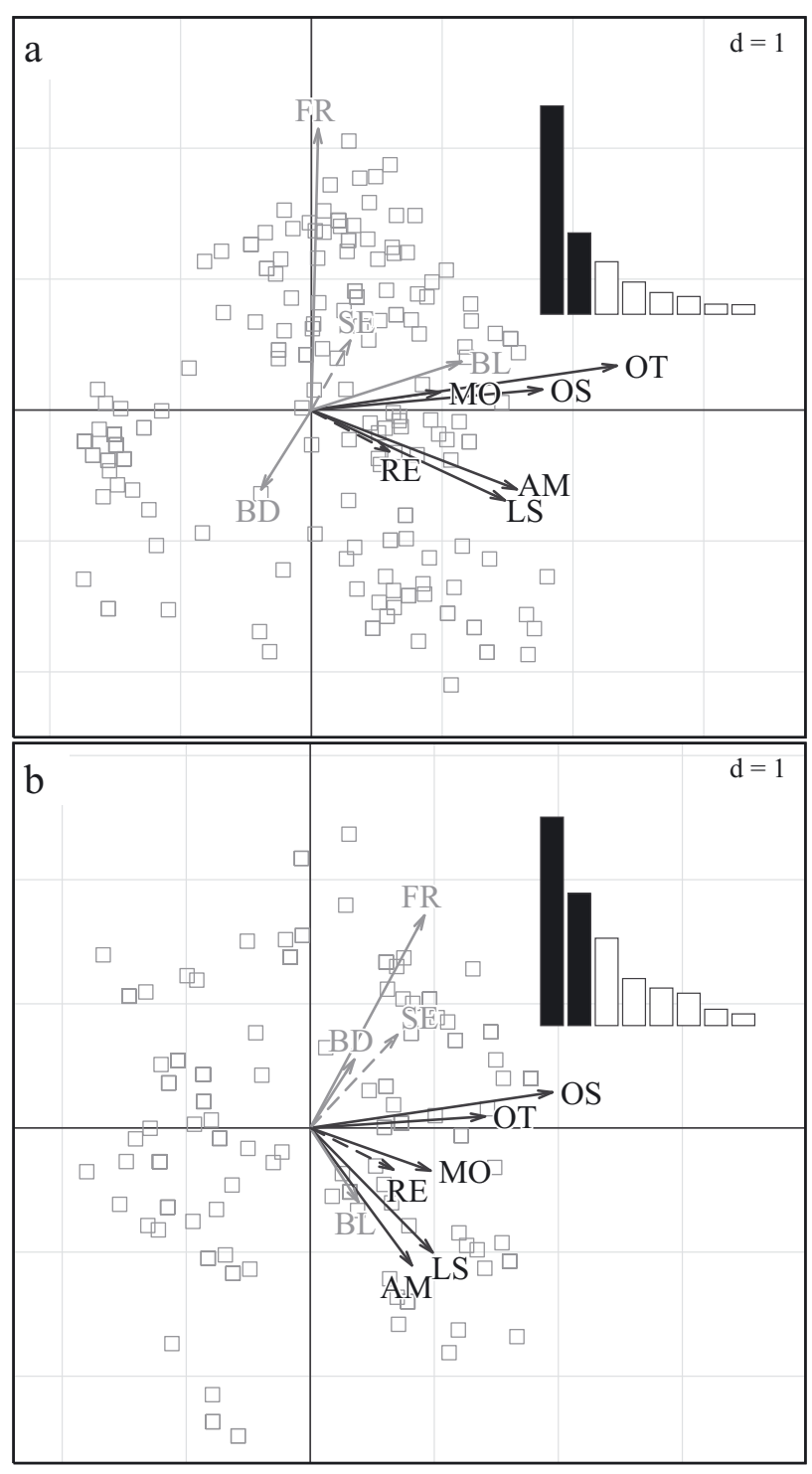

Fig. 3. Principal component analysis of biological trait covariances from taxa $\times$ standardised traits matrices. (a) Endobenthos from the Dutch EEZ. (b) Epibenthos from the Bay of Biscay. Bar diagrams, eigenvalues (black, axes 1 and 2). Grey arrows show traits of the sensitivity (SE) component; black arrows indicate traits of the recovery (RE) component. Dashed arrows, SE and RE components are projected as passive elements. Grey squares represent taxa. 'd' indicates the grid scale. AM: age at maturity; BD: burrowing depth; BL: body length; FR: fragility; LS: life span; MO: motility; OS: offspring size; OT: offspring type. Table S4.1 in Supplement 4 provides correlations between traits

studies, all recoverability traits covaried positively along the first axis. Adult traits (life span and age at maturity) diverged together from the combination of offspring traits (type and size), motility keeping an intermediate position. In contrast, sensitivity traits, more expressed along the second axis, were less covariant. Except for body length, traits were more correlated within than between sensitivity and recovery components; correlation matrices are provided in Table S5.1 in Supplement 5. Sensitivity and recoverability components were globally independent as displayed by their orthogonality (Dutch EEZ, $r=0.02, \mathrm{p}=0.768$; Bay of Biscay, $r=0.13, \mathrm{p}=$ 0.102). Both variables, projected as passive elements, showed similar norms (vector length), indicating that they contributed similarly to biological variations between taxa. This functional independence between sensitivity and recoverability suggests that both components could provide complementary information about short- and longer-term responses to trawling. Therefore, our first hypothesis was supported.

\subsection{Synthetic trait distributions}

The density distributions of sensitivity and recoverability components are shown in Fig. 4, indicating low proportions of sensitive and slow-to-recover taxa in both faunas. Individually, sensitivity and recoverability components of both communities were distributed similarly (Fig. 4a,b). Differences were observed between the 2 variants of vulnerability (SE + RE and SE $\times$ RE), both indicating slightly higher proportions of vulnerable taxa in the Bay of Biscay (Fig. 4c,d).

Fragile epibenthic species, including pennatulaceans (e.g. Funiculina quadrangularis, Pteroeides griseum), Alcyonium spp., Hymenodiscus coronata and crinoids (Antedon sp. and Leptometra celtica), were the most sensitive species encountered in the Bay of Biscay. Similarly, fragile species including shallow burrowers Acrocnida brachiata, Amphiura filiformis, Eupolymnia nebulosa, Phaxas pellucidus, Poecilochaetus serpens, Psammechinus miliaris, Ophiura sp. and Spiophanes bombyx were among the most sensitive taxa in the Dutch EEZ. Conversely, least sensitive taxa were deep burrowers, including the mud shrimps Callianassa sp. and Upogebia deltaura mostly sampled in the Dutch EEZ, hard-shelled taxa such as Pagurus bernhardus found in both study areas and small-bodied taxa including species of the amphipod genus Bathyporeia. In the Dutch EEZ, some highly abundant taxa, including A. brachiata, A. filiformis, Arctica islandica, Brissopsis lyrifera, Echinocardium sp., Mya spp., Pholoe minuta and Scoletoma fragilis, had higher vulnerability scores ( $\mathrm{SE}+\mathrm{RE}_{\text {; range }}$ 0.25-0.92). In the Bay of Biscay, vulnerability scores among the most abundant taxa 

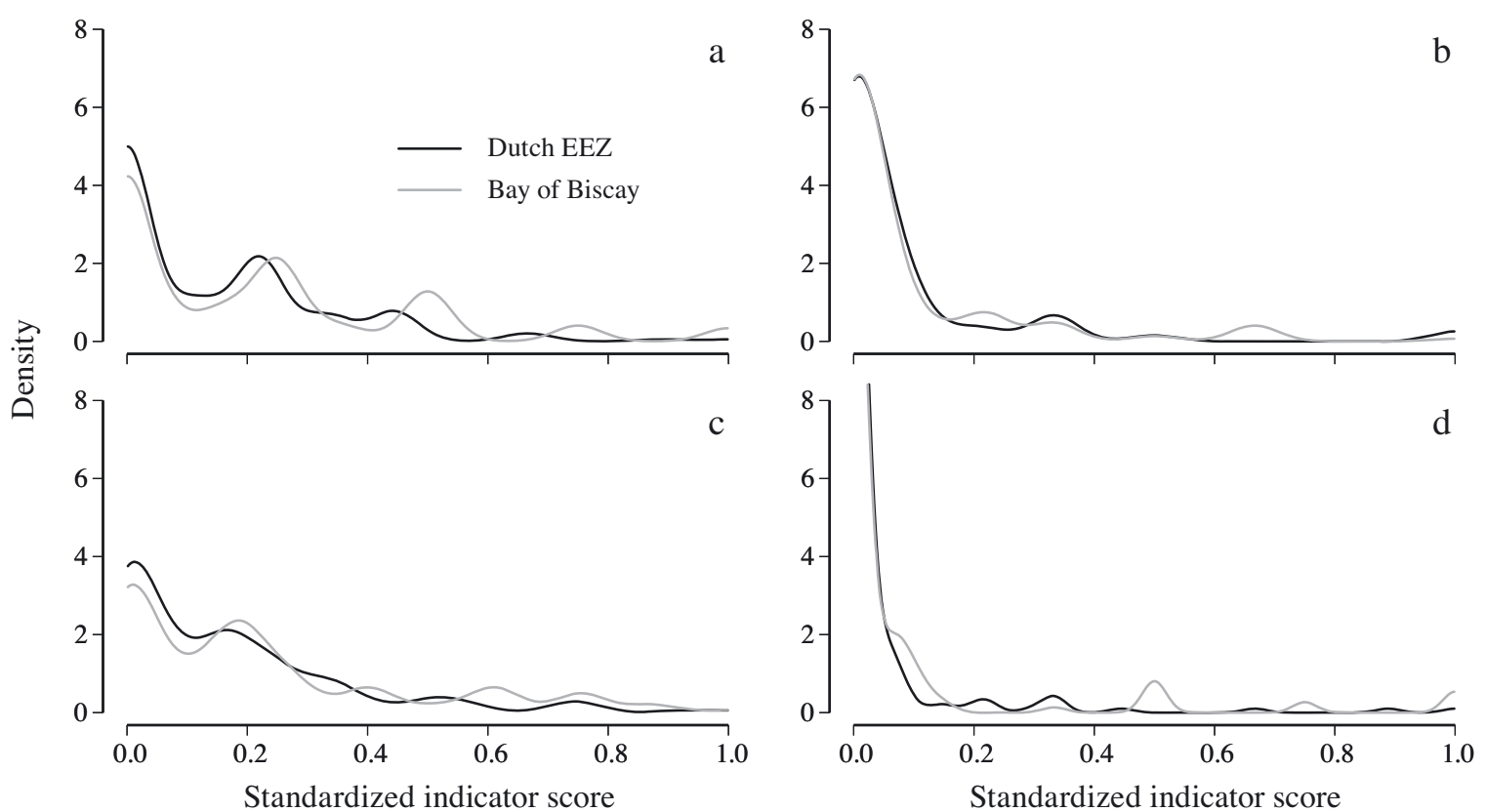

Fig. 4. Density distributions of (a) sensitivity (SE) and (b) recoverability (RE) components, and (c,d) vulnerability (SE + RE and $\mathrm{SE} \times \mathrm{RE}$, respectively); $x$-axis, standardised indicator score. As the number of taxa differs between the 2 case studies, data are standardised in order to only compare the shapes of the curves through probability densities. Below-curve area represents the density of taxa

were relatively lower, with the exception of the urchin Gracilechinus acutus and crinoids (Antedon sp. or Leptometra sp.) that ranged between 0.5 and 0.6. As expected, vulnerability scores for other abundant species were all below 0.5. Species of pennatulaceans (e.g. Funiculina quadrangularis), although relatively less abundant, had the highest vulnerability scores (RE + SE, range 0.63-1.00).

\subsection{Trawling intensity and confounding effects with environmental variables}

Trawling intensity (as SAR) was similarly distributed in both study areas, with low values dominating (Fig. 5a,b). However, the range of SAR values was significantly wider for the Bay of Biscay (25\% of SAR values above 4.6 ) than for the Dutch EEZ (maximal SAR = 4.7). In the Dutch EEZ, trawling intensity was strongly predicted by abiotic variables (trawling intensity regressed on abiotic variables, $R^{2}=0.78$ ). Most response variables were also strongly predicted by abi-
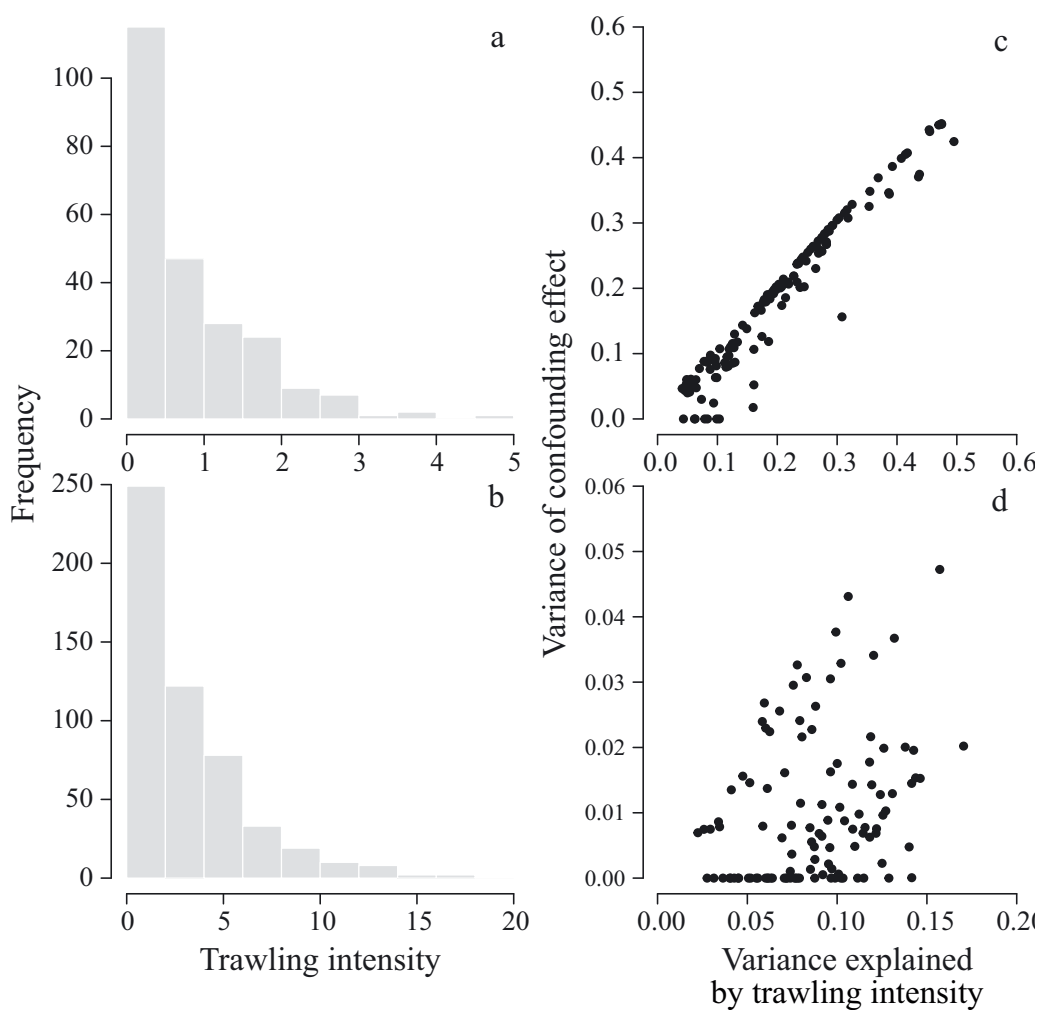

Fig. 5. Frequency distributions of trawling intensities expressed as swept area ratio for (a) the Dutch EEZ and (b) the Bay of Biscay. Also shown is the variance of response variables for individual traits and combinations of traits concurrently explained by abiotic variables and trawling intensity (confounding effect) plotted against variance explained by raw trawling intensity only for (c) the Dutch EEZ and (d) the Bay of Biscay. Each dot refers to a response variable (individual trait or combination of traits) for which the conditional trawling effect was significant (see Tables S5.1 \& S5.2 in Supplement 5) 
otic variables (Table S5.1). Consequently, increasing trawling intensity was inexorably accompanied by an increase in confounded effects of trawling intensity and environmental characteristics. This hampered the detection of true trawling effects on response variables following variation partitioning (Fig. 5c; Table S5.1). A similar trend, although detected (trawling vs. environment, $R^{2}=0.14$ ), was less pronounced in the Bay of Biscay (Fig. $5 d_{\text {i }}$ Table S5.2).

\subsection{Trait responses to trawling}

The results of our analyses (Table 2) show that, in general, trait combinations were more responsive to trawling intensity than single traits. Therefore, our second hypothesis $\left(H_{2}\right)$ was supported. As expected, when significant, all traits responded negatively to trawling, except offspring type and size, especially in the Bay of Biscay. Tables S5.1 \& S5.2 display complementary results for different sub-combinations of traits within SE and RE components, including confounding effects.

In the Dutch EEZ, relative biomass density was the most responsive to trawling, and not confounded with responses to environmental variables (Table S5.1, adjusted $R^{2}$ ranging from 0.02 to 0.15 ). Overall, individual trait responses were mostly insignificant, except offspring size based on relative biomass. Trait responses were highly obscured by confounding effects of abiotic variables, masking the effect of trawling intensity (Fig. 5c), with limited amounts of explained variance left when controlling for the effect of the environment (Table S5.1). In general, $\mathrm{SE}$ was less responsive than $\mathrm{RE}$, in spite of smaller confounding effects (average adjusted $R^{2}=$ 0.12 for SE against 0.33 for RE). Whereas all densities returned similar latitudinal contrasts in SE, RE and vulnerability (Figs. S6.1 \& S6.2 in Supplement 6 ; higher values in the north), the main spatial differences between SE and RE components were observed for absolute and relative biomass densities. Vulnerability based on the additive combina-

Table 2. Trait responses to trawling intensity. Values are partial $r$, Pearson's $r$-correlation coefficient between trait and trawling intensity after controlling for the effect of abiotic variables (partial regression). EEZ: exclusive economic zone; ns: not significant $(p \geq 0.05) ;$ SE: sensitivity; RE: recoverability; Absolute density: sum of taxon raw values in a sample; Relative density: taxon raw values divided by sample total and then summed

\begin{tabular}{|c|c|c|c|c|c|c|c|c|}
\hline \multirow[t]{2}{*}{ Case study } & \multirow[t]{2}{*}{ Component } & \multirow{2}{*}{ Response variable } & \multicolumn{3}{|c|}{ Absolute density $ـ$} & \multicolumn{3}{|c|}{ Relative density } \\
\hline & & & Biomass & Individual & Taxon & Biomass & Individual & Taxon \\
\hline \multirow[t]{12}{*}{ Dutch EEZ } & \multirow[t]{8}{*}{ Individual traits } & Body length & ns & ns & ns & ns & -0.25 & ns \\
\hline & & Fragility & ns & ns & ns & ns & -0.24 & ns \\
\hline & & Burrowing depth & ns & ns & ns & -0.20 & ns & ns \\
\hline & & Motility & ns & ns & ns & ns & ns & ns \\
\hline & & Age at maturity & ns & ns & ns & ns & ns & ns \\
\hline & & Life span & ns & ns & ns & ns & -0.25 & ns \\
\hline & & Offspring type & ns & ns & ns & ns & -0.23 & ns \\
\hline & & Offspring size & ns & ns & ns & -0.41 & ns & ns \\
\hline & Sensitivity & $\mathrm{SE}$ & $\mathrm{ns}$ & ns & ns & -0.39 & -0.30 & ns \\
\hline & Recoverability & $\mathrm{RE}$ & -0.25 & -0.32 & -0.28 & -0.39 & -0.23 & -0.37 \\
\hline & Vulnerability & $\mathrm{SE}+\mathrm{RE}$ & ns & ns & ns & -0.44 & -0.29 & ns \\
\hline & & $\mathrm{SE} \times \mathrm{RE}$ & -0.25 & ns & ns & -0.43 & -0.25 & ns \\
\hline \multirow[t]{12}{*}{ Bay of Biscay } & Individual traits & Body length & -0.21 & -0.22 & -0.24 & ns & ns & -0.35 \\
\hline & & Fragility & -0.34 & -0.28 & -0.29 & -0.24 & -0.28 & -0.32 \\
\hline & & Burrowing depth & -0.30 & -0.24 & -0.25 & -0.24 & -0.20 & -0.30 \\
\hline & & Motility & -0.32 & -0.34 & -0.35 & -0.25 & -0.29 & -0.31 \\
\hline & & Age at maturity & -0.22 & -0.23 & -0.25 & ns & -0.09 & -0.31 \\
\hline & & Life span & -0.23 & -0.20 & -0.21 & ns & ns & -0.14 \\
\hline & & Offspring type & -0.30 & -0.28 & -0.29 & -0.33 & -0.27 & -0.42 \\
\hline & & Offspring size & -0.35 & -0.38 & -0.39 & -0.29 & -0.38 & -0.41 \\
\hline & Sensitivity & $\mathrm{SE}$ & -0.36 & -0.38 & -0.39 & -0.29 & -0.42 & -0.42 \\
\hline & Recoverability & $\mathrm{RE}$ & -0.39 & -0.36 & -0.35 & -0.26 & -0.28 & -0.26 \\
\hline & Vulnerability & $\mathrm{SE}+\mathrm{RE}$ & -0.41 & -0.40 & -0.41 & -0.36 & -0.45 & -0.43 \\
\hline & & $\mathrm{SE} \times \mathrm{RE}$ & -0.29 & -0.32 & -0.27 & -0.20 & -0.22 & -0.21 \\
\hline
\end{tabular}




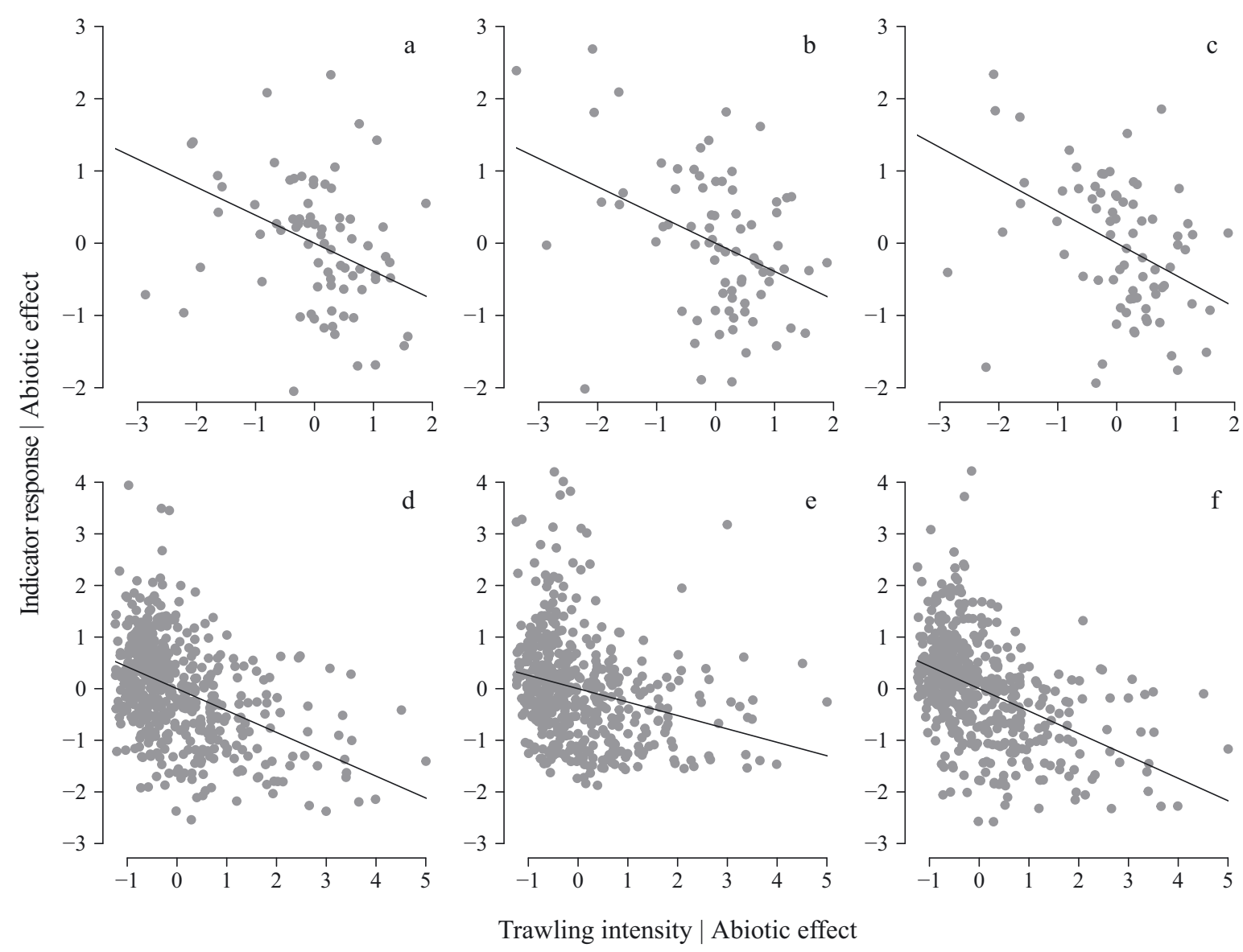

Fig. 6. Strongest indicator responses obtained for each case study. (a-c) Dutch EEZ, relative biomass density; (d-f) Bay of Biscay, relative number of taxa. Variables are standardised residuals from regression on abiotic variables (symbol ' $\mathrm{l}$ ', partial regression). (a,d) Sensitivity. (b,e) Recoverability. (c,f) Vulnerability = Sensitivity + Recoverability

tion of SE and RE for relative biomass responded most strongly (Fig. 6a-C) and SE and RE spatial patterns were the most contrasted with marked local complementarities (Fig. $7 \mathrm{a}-\mathrm{c}$ ).

In the Bay of Biscay, the 3 types of densities (and their relative counterparts) responded similarly, with higher partial correlations for relative individual and taxon densities. The spatial distribution of the 2 components corresponded largely to some of the major habitats in the Bay of Biscay (Fig. 7d,e; Figs. S6.3 \& S6.4). In addition to smaller confounding effects, explained variances were often higher than in the Dutch EEZ (Tables S5.1 \& S5.2). Vulnerability responded most strongly, and this was also the case with the additive combination of SE and RE (Fig. $6 \mathrm{~d}, \mathrm{e}$ ). The additive combination of SE and RE, as well as the 2 components separately, showed similar spatial patterns notwithstanding the type of densities. Both components corresponded largely to some of the major habitats in the Bay of Biscay (Fig. $7 \mathrm{~d}_{1} \mathrm{e}_{\text {; }}$ Figs. S6.3 \& S6.4).

\section{DISCUSSION}

\subsection{Responsiveness of benthic community traits to trawling}

The response of benthic community traits to trawling was consistent with our expectations. Corroborating the findings of Bolam et al. (2014), our results clearly advocate for the use of multiple traits rather than a single trait in synecological studies. While recent studies proposed life span as the single trait determining the benthic community response (e.g. the 'longevity approach', Hiddink et al. 2019, Rijnsdorp et al. 2020), this (1) assumes that the single trait adequately represents the recoverability component (RE) and (2) ignores the sensitivity component (SE). Out of 12 tests ( 6 densities in each case study), life span was significant only 5 times compared to RE, which was always significant. This supports the contention that densities of long-lived species may lose their indicator potential beyond a certain level of 

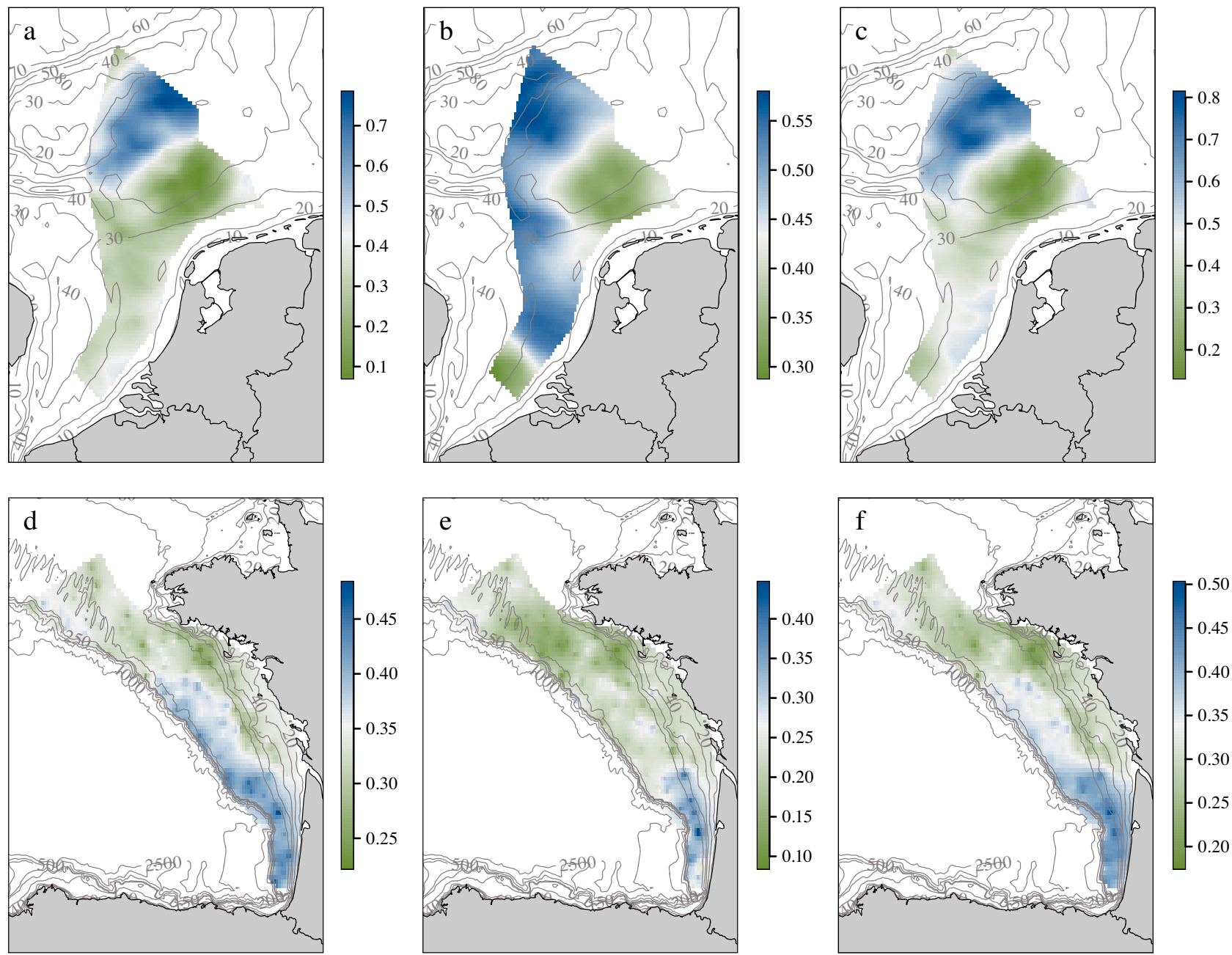

Fig. 7. Interpolation maps of the most responsive variables for $(a-c)$ Dutch EEZ, (d-f) Bay of Biscay. (a,d) Sensitivity (SE), (b,e) recoverability $(\mathrm{RE})$ and $(\mathrm{c}, \mathrm{f})$ vulnerability $(\mathrm{SE}+\mathrm{RE})$. Values are organism densities multiplied by trait scores, rescaled to the interval [0-1]

trawling intensity, whereas the alternative, relative maturity (RM), may indicate fishing effects, even at high and prolonged trawling intensities.

In the Dutch EEZ, the lower SE responsiveness may be due to a much higher proportion of buried species compared to purely epibenthic ones. Only 13 taxa with a high (> median) SE score ( $7 \%$ of the total) were epibenthic, against 35 taxa $(18 \%)$ of deep burrowers $(>5 \mathrm{~cm})$. In contrast, 68 taxa with high SE scores $(40 \%)$ in the Bay of Biscay were epibenthic and none were deep burrowers, probably explaining the regular SE responsiveness there. Significant responses of SE in the Dutch EEZ, only observed for relative biomass and individual densities, may have been due to dominant epibenthic or shallowdwelling taxa with high SE scores. We cannot provide accurate estimates of trawl mortality as a func- tion of burrowing depth, as no information on gear penetration depth was available, and it is known that the same gear can have different effects in different sediment types (Kaiser et al. 2006). However, there is good evidence that vulnerability is a function of burrowing depth, especially in the Bay of Biscay. Firstly, Tiano et al. (2020) experimentally compared the effects of 2 contrasting trawling techniques (pulse and tickler chain trawls; both in soft mud) on benthic fauna; as expected, densities of epibenthic fauna and shallow burrowers were depleted, but no significant difference was detected between the 2 trawling techniques. Secondly, a larger proportion of the fauna from the Bay of Biscay was epibenthic (Fig. S3; almost $70 \%$ of the taxa, compared to less than $15 \%$ in the Dutch EEZ) and was likely more exposed to trawling gears than the fauna from the Dutch EEZ, 
where $>35 \%$ of the taxa could be found $>5 \mathrm{~cm}$ deep (cf $<10 \%$ in the Bay of Biscay). Comparatively, the usual penetration depths of bottom trawls rarely exceed 5-10 cm (Eigaard et al. 2016).

Our analyses using biomass densities of endobenthos in the Dutch EEZ recorded a large area of low sensitivity centred on the Frisian Front (Fig. $7 a-c$, around $54^{\circ} \mathrm{N}$ ). There, the very deep burrowers Callianassa sp. and Upogebia deltaura comprise a large proportion of total benthic biomass. In contrast, vulnerability based on number of taxa is higher in this area due to high SE and/or RE scores of many species with relatively low biomass densities (Fig. S6.1i-k). In the Bay of Biscay, the continental shelf encompasses a patchwork of habitats, resulting in different processes driving apparently similarly low SE values. In the north-eastern part (Fig. $7 \mathrm{~d}, 45.5^{\circ}-46.5^{\circ} \mathrm{N}$ ), a muddy area named 'Grande Vasière', low SE values result from the dominance of burrowing organisms and the presence of the most sensitive epibenthic species with densities greatly reduced by intensive fishing in that area over several decades. In the sandy habitats of the transitional area between the Celtic Sea and the Bay of Biscay (around $47.5^{\circ} \mathrm{N}$ ), low SE values reflect high biomass of some trawling-resistant species including the anemone Actinauge sp. and the paguroid Pagurus prideaux. Highest SE values in the southernmost areas were mainly due to the dominance of sensitive species including pennatulaceans (Pteroeides spp. or Funiculina spp.) and crinoids (Leptometra celtica). The latter species is also found in patches in the central area of the Bay of Biscay between the $100 \mathrm{~m}$ isobath and the shelf-break where high SE values were also recorded.

For benthic community status assessments, the choice of biomass, individual or taxon densities may be determined by the focus of the assessment. For example, trawling effects on biodiversity might best be assessed using taxon densities. Conversely, effects on foodweb functioning would be more meaningfully established based on biomass, and individual density may be less appropriate (as it is biased towards representing the most abundant species) for expressing multi-faceted and often ill-defined concepts such as community health or seafloor integrity (as used in the Marine Strategy Framework Directive). In the Dutch EEZ, stronger relationships for traits weighted by biomass were found than for traits weighted by individual or taxon densities, especially when relative densities were applied. High biomass densities can indicate the presence of old individuals of vulnerable species (i.e. those requiring sufficient time without disturbance to ensure reproductive success), whereas high numbers of individuals can simply reflect high numbers of young vulnerable organisms at the beginning of a recovery period or high numbers of resilient smaller and shorter-lived organisms, as evidenced by abundance-biomass comparisons along successions in the marine benthos (Pearson \& Rosenberg 1978, Warwick \& Clarke 1994, Diaz \& Rosenberg 1995). In the Bay of Biscay, the consistent responsiveness among the different types of densities may be explained by steeper species richness gradients compared to other densities (Figs. S6.3 \& S6.4), coupled with the negligible confounding effects of environmental variables in this area (see Section 4.2).

\subsection{Confounding effects}

The strong confounding environmental effects encountered in the Dutch EEZ were probably responsible for the absence of significant responses for many variables, as explained variances were of similar magnitudes (Table S5.1). Consequently, removing the confounding effect from the total effect left only small amounts of variance in the benthic community traits to be explained by trawling intensity. In the Dutch EEZ, trawling intensity increases from the deeper water in the north to the shallow water in the south, as does primary productivity (correlated to trawling intensity, $r=0.66, \mathrm{p}<0.001$ ), so that it is difficult to appraise the true trawling effect on what is effectively a correlated gradient. The response of benthic communities could therefore be the result of an increase in trawling intensity, a change in habitat, or both. This was also observed for species richness by Duineveld et al. (1992). In our study, this is demonstrated by the generally high level of variance in abiotic variables (Table S5.1). Besides, opposing directions of change in trawling intensity and a given indicator could mask the effects of trawling disturbance buffered by environmental suitability (i.e. compensating depletion). As observed in the Dutch EEZ, the use of relative densities may, to some extent, mitigate the confounding effect of production gradients by emphasising the functional nature of communities more compared to analyses based on species richness or total organism density (Beauchard et al. 2017).

Few benthic studies have explicitly taken confounding effects into account (Lindegarth et al. 2000, Hinz et al. 2009, Reiss et al. 2009, Jac et al. 2020). To our knowledge, no work developing composite trait 
indicators has sought to statistically validate this important aspect. Several studies were previously carried out along gradients of commercial fishing intensity, some of which probably involved correlations with other forms of anthropogenic physical disturbance and, importantly, environmental variability. The conclusions drawn from such studies should be considered with caution. Variation in fishing intensity often follows variation in fish abundance and habitat suitability, both of which are driven by variation in the environment (Pommer et al. 2016). To truly disentangle fishing effects, long-term fishing exclusion from different habitats (i.e. those with different degrees of vulnerability) would offer better experimental contexts (Hall 1999, Gray et al. 2006).

\subsection{Developing a trait-based vulnerability indicator}

Here, we present a generic approach that can be used to develop a trait-based indicator to assess the vulnerability of benthic communities to fishinginduced physical disturbance. This approach is based on 2 processes derived from a mechanistic understanding of trawling effects on the benthic community, i.e. sensitivity and recoverability, and is well-grounded in benthic ecological theories. We chose to offer a generic approach so that it can be adjusted to fit specific contexts in terms of data availability, knowledge of the benthic fauna and traits selected to express both $\mathrm{SE}$ and RE processes. As trait scores take the value 0 in species that are not vulnerable, null scores of combined variables are likely to increase with more traits, leading to a larger number of species that do not contribute to the community score. This ensures that non-null scores arise from vulnerable species which are not resistant and with limited resilience. In areas where benthic communities are extremely impoverished, it may be necessary to limit the number of traits considered, in order to minimise the number of null scores. However, in the case of correlated traits such as in the RE component, the number of null scores of combined variables is limited as vulnerable species have high scores for most of the traits. Conversely, the use of the SE component may be more conservative for the detection of trawling effects, given the strong independence of SE traits.

Further work, using data collected under controlled conditions, is recommended before deciding on a definitive version of an indicator combining both $\mathrm{SE}$ and RE components. Indeed, there may not be a single 'best' vulnerability indicator but a range of similar ones that are tailored to the benthic community being studied, how it was sampled and the overall local conditions. For example, a benthic community not impacted by trawling previously, would be characterised by a large spread of SE and RE scores due to higher proportions of vulnerable species. When trawling commences, the relative contributions of SE and RE components to the decreasing vulnerability indicator are expected to change over time, i.e. first dominated by the SE and later by the RE component. After the initial trawl pass, it can reasonably be assumed that the first responding individuals/species will be those with higher SE scores (e.g. sea pens). Then, under continued and frequent trawling that does not allow recovery, only species with sufficient resilience relative to trawling intensity will survive continued trawling, so the SE score remains low. Once fishing ceases, indicator response is determined, chronologically, by the SE component, followed by the RE component dominated initially by high relative maturity (RM) scores and later by life span. After implementation of a marine protected area, for example, the indicator responsiveness would be determined in the short term by SE and in the long term by RE. In our case study areas, both of which involved trawled communities, SE responses may be considerably smaller than what might have been expected under pristine, or at least less degraded, circumstances. As such, both SE and RE need to be included in a benthic vulnerability indicator that is expected to perform well under very different circumstances.

The range of variation in trawling intensity was large enough in our study to detect significant responses of some trait-based indicator components. However, the general lack of responsiveness of life span, an important recoverability trait, may be explained in both case studies by temporal contingencies. In both areas, the presence of species with potentially high scores for both SE and RE was observed long ago (Houziaux et al. 2011). The long history of sustained bottom trawling may have extirpated a substantial proportion of the vulnerable epibenthic fauna. Bottom trawling is known to have affected European coastal areas since the $13^{\text {th }}$ century (de Groot 1984), expanding to further and deeper areas in the following centuries (Joubin 1922). The resulting lack of lightly impacted areas, and hence a limited variation in SE, RE and vulnerability among both endo- and epibenthic communities, may have masked greater RE responsiveness. Nevertheless, we cannot exclude some limitations from our spatial sampling resolution to properly 
detect local patches of vulnerable epibenthic fauna as evidenced by the recent discovery of a Sabellaria spinulosa reef in an area of intense demersal fishing within the Dutch EEZ (van der Reijden et al. 2019).

Lastly, the inclusion of other important traits could have enhanced the performance of our approach. In the SE component, body regeneration could have been relevant, but its documentation remains questionable for many species such as bivalves exposing their siphons to predators or regenerating shell. Also, as illustrated by the noticeable responsiveness of offspring type and size, offspring traits should deserve more attention. Besides, information on larval settlement cues could have improved the RE component. Different species with differing growth rates and life spans require cues for settling, such as the presence of adults or aspects of the physico-chemical nature of the sea floor (Pechenik 1990, Pawlik 1992). Given the effects of bottom trawling on the sediment (Schwinghamer et al. 1998), larval settlement is likely to be impaired by removing adults or by altering the nature of the sediment.

\subsection{Conclusions}

Based on a theoretically sound mechanistic understanding of trawling effects on the benthic community, this study advocates the use of multiple biological traits for assessing the status of seabed habitats specifically in relation to trawling-induced physical disturbance. We emphasise the complementarity of $\mathrm{SE}$ and RE components and their relative importance depending on the study context. In this study, their independence is a major finding, implying that vulnerability cannot be fully understood using a single trait or several ones only reflecting the intrinsic rate of natural increase. Our results show that an assessment of the status of seabed habitats, and how these are affected by physical disturbance, requires the full consideration of the benthic community, including both endo- and epibenthic components, each needing different sampling techniques.

Our generic approach to the development of a benthic community vulnerability indicator can be adapted to specific contexts. Depending on the availability of data from monitoring programmes, such as type of fauna sampled (endo- or epibenthos), faunal data recorded (numbers, biomass) and availability of trait information, an indicator can be created that is likely to perform well even in areas with a long history of exploitation.
Acknowledgements. O.B. acknowledges funding from the Gieskes Strijbis Fonds as part of the DISCLOSE project (https://discloseweb.webhosting.rug.nl/). M.S. acknowledges support from the UK Department for Environment, Food and Rural Affairs via project SLA44: Marine Biodiversity Advice; and from the Natural Environment Research Council and the UK Department for Environment, Food and Rural Affairs via grant NE/L003279/1 (Marine Ecosystems Research Programme). P.J.S. acknowledges support from the UK Natural Environment Research Council (NE/L003279/1, Marine Ecosystems Research Programme and NE/R015953/1, Climate Linked Atlantic Sector Science). G.J.P. acknowledges funding from the Dutch Ministry of Agriculture, Nature and Food Quality for the purposes of Policy Support Research (project no. BO-43-021.02-002). This work was carried out as part of the ICES Working Group on Biodiversity Science. We thank 3 anonymous reviewers for constructive comments on the manuscript.

\section{LITERATURE CITED}

Baretta JW, Ebenhöh W, Ruardij P (1995) The European regional seas ecosystem model, a complex marine ecosystem model. Neth J Sea Res 33:233-246

*Beauchard O, Veríssimo $\mathrm{H}$, Queirós AM, Herman PMJ (2017) The use of multiple biological traits in marine community ecology and its potential in ecological indicator development. Ecol Indic 76:81-96

* Bergman MJN, van Santbrink JW (2000) Mortality in megafaunal benthic populations caused by trawl fisheries on the Dutch continental shelf in the North Sea in 1994. ICES J Mar Sci 57:1321-1331

Bitschofsky F, Forster S, Scholz J (2011) Regional and temporal changes in epizoobiontic bryozoan-communities of Flustra foliacea (Linnaeus, 1758) and implications for North Sea ecology. Estuar Coast Shelf Sci 91:423-433

Bolam SG, Coggan RC, Eggleton J, Diesing M, Stephens D (2014) Sensitivity of macrobenthic secondary production to trawling in the English sector of the Greater North Sea: a biological trait approach. J Sea Res 85:162-177

* Bouysse P, Lesueur P, Klingebiel A (1986) Carte des sédiments superficiels du plateau continental du Golfe de Gascogne - Partie septentrionale au 1/500000. BRGM \& IFREMER. https://sextant.ifremer.fr/record/ea0b61b071c6-11dc-b1e4-000086f6a62e/en/index.htm

Charnov EL (1993) Life history invariants. Some explorations of symmetry in evolutionary ecology. Oxford University Press, Oxford

Chessel D, Dufour AB, Thioulouse J (2004) The ade4 package - I: One-table methods. R News 4:5-10

Convention for the Protection of the Marine Environment of the North-East Atlantic (2017) OSPAR data and information management. https://odims.ospar.org/layers/ geonode:ospar_bottom_f_intensur_2009_01_002

Daan R, Mulder M (2009) Monitoring the invertebrate benthic fauna in the Dutch sector of the North Sea 19912005: an overview. Rep 2009-5. NIOZ, Texel

* de Groot SJ (1984) The impact of bottom trawling on benthic fauna of the North Sea. Ocean Coast Manag 9:177-190

* de Juan S, Demestre M (2012) A trawl disturbance indicator to quantify large scale fishing impact on benthic ecosystems. Ecol Indic 18:183-190

de Juan S, Hinz H, Sartor P, Vitale S and others (2020) Vulnerability of demersal fish assemblages to trawling activities: a traits-based index. Front Mar Sci 7:44 
Diaz RJ, Rosenberg R (1995) Marine benthic hypoxia: a review of its ecological effects and the behavioural response of benthic macrofauna. Oceanogr Mar Biol Annu Rev 33:245-303

Duineveld GCA, de Wilde PAWJ, Kok A (1992) A synopsis of the macrobenthic assemblages and benthic ETS activity in the Dutch sector of the North Sea. Neth J Sea Res 28: $125-138$

Eigaard OR, Bastardie F, Breen M, Dinesen GE and others (2016) Estimating seabed pressure from demersal trawls, seines, and dredges based on gear design and dimensions. ICES J Mar Sci 73(Suppl 1):i27-i43

EMODnet Bathymetry Consortium (2018) EMODnet Digital Bathymetry (DTM 2018). https://doi.org/10.12770/18ff0 d48-b203-4a65-94a9-5fd8b0ec35f6

Foveau A, Vaz S, Desroy N, Kostylev VE (2017) Processdriven and biological characterisation and mapping of seabed habitats sensitive to trawling. PLOS ONE 12: e0184486

Gan X, Fernandez IC, Guo J, Wilsond M, Zhaoe Y, Zhou B, $\mathrm{Wu} J$ (2017) When to use what: methods for weighting and aggregating sustainability indicators. Ecol Indic 81: 491-502

Giangrande A (1997) Polychaete reproductive patterns, life cycles and life histories: an overview. Oceanogr Mar Biol Annu Rev 35:323-386

Giangrande A, Geraci S, Belmonte G (1994) Life-cycle and life-history diversity in marine invertebrates and the implications in community dynamics. Oceanogr Mar Biol Annu Rev 32:305-333

González-Irusta JM, De la Torriente A, Punzón A, Blanco M, Serrano A (2018) Determining and mapping species sensitivity to trawling impacts: the BEnthos Sensitivity Index to Trawling Operations (BESITO). ICES J Mar Sci 75: 1710-1721

Gray JS, Dayton P, Thrush S, Kaiser MJ (2006) On effects of trawling, benthos and sampling design. Mar Pollut Bull 52:840-843

Hall SJ (1999) The effects of fishing on marine ecosystems and communities. Blackwell Science, Oxford

Hiddink JG, Jennings S, Sciberras M, Szostek CL and others (2017) Global analysis of depletion and recovery of seabed biota after bottom trawling disturbance. Proc Natl Acad Sci USA 114:8301-8306

*Hiddink JG, Jennings S, Sciberras M, Bolam SG and others (2019) Assessing bottom trawling impacts based on the longevity of benthic invertebrates. J Appl Ecol 56: 1075-1084

Hintzen N, Aerts G, Poos JJ, Van der Reijden KJ, Rijnsdorp $A D$ (2021) Quantifying habitat preference of bottom trawling gear. ICES J Mar Sci 78:172-184

Hinz H, Prieto V, Kaiser MJ (2009) Trawl disturbance on benthic communities: chronic effects and experimental predictions. Ecol Appl 19:761-773

Hinz H, Törnroos A, de Juan S (2021) Trait-based indices to assess benthic vulnerability to trawling and model loss of ecosystem functions. Ecol Ind 126:107692

Houziaux JS, Fettweis M, Francken F, Van Lancker V (2011) Historic (1900) seafloor composition in the BelgianDutch part of the North Sea: a reconstruction based on calibrated visual sediment descriptions. Cont Shelf Res 31:1043-1056

International Council for the Exploration of the Sea (2017a) Report of the Workshop to evaluate regional benthic pressure and impact indicator(s) from bottom fishing
(WKBENTH). 28 February - 3 March 2017, Copenhagen, Denmark. ICES CM 2017/ACOM

International Council for the Exploration of the Sea (2017b) Spatial data layers of fishing intensity/pressure per gear type for surface and subsurface abrasion, for the years 2009 to 2016 in the OSPAR regions (ver2, 22 January, 2019): ICES data product release. https://doi.org/10. 17895/ices.data.4685

Jac C, Desroy N, Certain G, Foveau A, Labrune C, Vaz S (2020) Detecting adverse effect on seabed integrity. Part 1: Generic sensitivity indices to measure the effect of trawling on benthic mega-epifauna. Ecol Indic 117: 106631

Joubin ML (1922) Les coraux de mer profonde nuisibles aux chalutiers. Notes et Mémoires 18. Office Scientifique et Techniques des Pêches Maritimes, Paris

Kaiser MJ, Clarke KR, Hinz H, Austen MCV, Somerfield PJ, Karakassis I (2006) Global analysis of response and recovery of benthic biota to fishing. Mar Ecol Prog Ser 311: $1-14$

Kindsvater HK, Mangel M, Reynolds JD, Dulvy NK (2016) Ten principles from evolutionary ecology essential for effective marine conservation. Ecol Evol 6:2125-2138

Kleyer M, Dray S, de Bello F, Lepš J and others (2012) Assessing species and community functional responses to environmental gradients: which multivariate methods? J Veg Sci 23:805-821

Lazure P, Dumas F (2008) An external-internal mode coupling for a 3D hydrodynamical model for applications at regional scale (MARS). Adv Water Resour 31: 233-250

Legendre P, Legendre L (2012) Numerical ecology, $3^{\text {rd }}$ edn. Elsevier, Amsterdam

* Lindegarth M, Valentinsson D, Hansson M, Ulmestrand M (2000) Interpreting large-scale experiments on effects of trawling on benthic fauna: an empirical test of the potential effects of spatial confounding in experiments without replicated control and trawled areas. J Exp Mar Biol Ecol 245:155-169

MacDonald DS, Little M, Eno NC, Hiscock K (1996) Disturbance of benthic species by fishing activities: a sensitivity index. Aquat Conserv 6:257-268

Mahe JC, Laffargue P (1987) EVHOE —EValuation Halieutique Ouest de l'Europe. https://doi.org/10.18142/8

*Marine Ecosystem Research Programme (2021) Marine Ecosystem Research Programme Trait Explorer. https://www. marine-ecosystems.org.uk/Trait_Explorer

* Mérillet L, Mouchet M, Robert M, Salaün M, Schuck L, Vaz S, Kopp D (2018) Using underwater video to assess megabenthic community vulnerability to trawling in the Grande Vasière (Bay of Biscay). Environ Conserv 45: 163-172

Oksanen J, Blanchet G, Kindt R, Legendre P and others (2010) Vegan: community ecology package. R package version 2.5-6. https://cran.r-project.org/package=vegan

Pawlik JR (1992) Chemical ecology of the settlement of benthic marine invertebrates. Oceanogr Mar Biol Annu Rev 30:273-335

Pearson TH, Rosenberg R (1978) Macrobenthic succession in relation to organic enrichment and pollution of the marine environment. Oceanogr Mar Biol Annu Rev 16: 229-311

*Pechenik JA (1990) Delayed metamorphosis by larvae of benthic marine invertebrates: Does it occur? Is there a price to pay? Ophelia 32:63-94 
Pechenik JA (1999) On the advantages and disadvantages of larval stages in benthic marine invertebrate life cycles. Mar Ecol Prog Ser 177:269-297

Pitcher CR, Ellis N, Jennings S, Hiddink JG and others (2017) Estimating the sustainability of towed fishinggear impacts on seabed habitats: a simple quantitative risk assessment method applicable to data-limited fisheries. Methods Ecol Evol 8:472-480

Pommer CD, Olesen M, Hansen JLS (2016) Impact and distribution of bottom trawl fishing on mud-bottom communities in the Kattegat. Mar Ecol Prog Ser 548:47-60

R Core Team (2020) R: a language and environment for statistical computing. R Foundation for Statistical Computing, Vienna

Reiss H, Greenstreet SPR, Sieben K, Ehrich S and others (2009) Effects of fishing disturbance on benthic communities and secondary production within an intensively fished area. Mar Ecol Prog Ser 394:201-213

Rijnsdorp AD, Bolam SG, Garcia C, Hiddink JG, Hintzen NT, van Denderen PD, van Kooten T (2018) Estimating sensitivity of seabed habitats to disturbance by bottom trawling based on the longevity of benthic fauna. Ecol Appl 28: $1302-1312$

Rijnsdorp AD, Hiddink JG, van Denderen PD, Hintzen NT and others (2020) Different bottom trawl fisheries have a differential impact on the status of the North Sea seafloor habitats. ICES J Mar Sci 77:1772-1786

Schwinghamer P, Gordon DC, Rowell TW, Prena J, McKeown DL, Sonnichsen G, Guigné JY (1998) Effects of experimental otter trawling on surficial sediment proper-

Editorial responsibility: Rochelle D. Seitz,

Gloucester Point, Virginia, USA

Reviewed by: 3 anonymous referees ties of a sandy-bottom ecosystem on the Grand Banks of Newfoundland. Conserv Biol 12:1215-1222

Sciberras M, Hiddink JG, Jennings S, Szostek CL and others (2018) Response of benthic fauna to experimental bottom fishing: a global meta-analysis. Fish Fish 19: 698-715

* SHOM (Service hydrographique et océanographique de la marine) (2014) Information géographique maritime et littorale de référence. https://datashom.fr

* Tiano JC, van der Reijden KJ, O'Flynn S, Beauchard O and others (2020) Experimental bottom trawling finds resilience in large-bodied infauna but vulnerability for epifauna and juveniles in the Frisian Front. Mar Environ Res 159:104964

* Tyler-Walters H, Roger SI, Marshall CE, Hiscock K (2009) A method to assess the sensitivity of sedimentary communities to fishing activities. Aquat Conserv 19:285-300

Valiela I (2015) Marine ecological processes, $3^{\text {rd }}$ edn. Springer-Verlag, New York, NY

* van Denderen PD, Hintzen NT, van Kooten T, Rijnsdorp AD (2015) Temporal aggregation of bottom trawling and its implication for the impact on the benthic ecosystem. ICES J Mar Sci 72:952-961

van der Reijden KJ, Koop L, O'Flynn S, Garcia S and others (2019) Discovery of Sabellaria spinulosa reefs in an intensively fished area of the Dutch Continental Shelf, North Sea. J Sea Res 144:85-94

Warwick RM, Clarke KR (1994) Relearning the ABC: taxonomic changes and abundance/biomass relationships in disturbed benthic communities. Mar Biol 118:739-744

Submitted: May 7, 2021

Accepted: July 22, 2021

Proofs received from author(s): September 24, 2021 